\title{
Hemorrhagic intracranial distal (cortical) dissections: five cases and a literature review
}

\author{
Carlos Michel Albuquerque Peres ${ }^{1}$, Rene Anxionnat ${ }^{2}$, Serge Bracard ${ }^{3}$
}

Serviço de Neurorradiologia Diagnóstica e Terapêutica, Université Lorraine, Nancy, França. Hospital Santa Júlia, Manaus, AM, Brasil.

\begin{abstract}
Objective: To describe and analyze five cases of symptomatic intracranial spontaneous cortical dissections and a review of the literature relating to this disorder. Method: Retrospective analysis of patients undergoing investigation for intracranial hemorrhage. Data were compiled from the medical file and PACS of the Nancy University Hospital. Results: Of 350 patients who underwent investigation for spontaneous intracranial hemorrhage, five patients (four women) harbored intracranial distal dissections, with no evidence of infection, trauma, arterial hypertension, vasculitis. The patients age ranged from 35 to 77 years (mean age 50.8 years). No patient presented with a poor grade SAH (Hunt and Hess grade IV or V). All patients presented with headache. The localization of the vessel abnormality was equally distributed between the anterior and posterior circulation. All patients, except one, harbored an aneurysmal sac angiographically detectable. Conclusion: Dissecting aneurysms of the intracranial distal/cortical arteries are exceedingly rare vascular lesions that produce neurologic symptoms related to their topography and hemorrhagic or ischemic nature. In the aneurysmal forms, the treatment in an urgent fashion may be considered if we consider the risk of re-hemorrhage. The first-choice treatment is coil occlusion of the involved artery at the level of the dissection.
\end{abstract}

\section{KEYWORDS}

Aneurysm dissecting, intracranial hemorrhages, endovascular procedures, embolization therapeutic.

\section{RESUMO}

Dissecções hemorrágicas intracranianas distais (corticais): cinco casos e revisão da literatura Objetivo: Descrever e analisar cinco casos de dissecção intracraniana de artérias distais espontâneas sintomáticas, com revisão da literatura. Método: Análise retrospectiva dos prontuários e imagens de tomografia, ressonância e angiografia. Os dados foram compilados do arquivo de imagens eletrônicas em formato DICOM por meio do sistema PACS do Hospital Universitário de Nancy, França. Resultados: De 350 pacientes investigados por hemorragia intracraniana espontânea, foram identificados cinco pacientes (quatro do sexo feminino) com aneurismas intracranianos distais, sendo descartadas as etiologias habituais (infecção, trauma, hipertensão arterial, vasculite). A média de idade foi de 50,8 anos, com mínima de 35 e máxima de 77 anos. Nenhum paciente estava com hemorragia de alto grau (HuntHess grau 4 ou 5). Todos tiveram cefaleia súbita como sintoma inicial. A localização da anormalidade vascular foi igualmente distribuída entre a circulação anterior e posterior. Todos os pacientes, exceto um, apresentavam aneurisma angiograficamente detectável. Conclusão: Pequenas hemorragias intracranianas em vasos corticais são frequentemente encontradas, mas raramente investigadas. Aneurismas dissecantes das artérias distais/corticais são lesões extremamente raras que produzem sintomas relacionados a sua topografia e natureza isquêmica ou hemorrágica. A história natural dessas lesões é pouco conhecida ou documentada. Aneurismas devem ser ocluídos preferencialmente com micromolas, evitando ressangramento.

\section{PALAVRAS-CHAVE}

Aneurisma dissecante, hemorragias intracranianas, procedimentos endovasculares, embolização terapêutica.

1 Neurocirurgião e neurorradiologista terapêutico do Hospital Santa Júlia, Manaus, AM, Brasil.

2 Neurorradiologista do Serviço de Neurorradiologia do Centro Hospitalar Universitário de Nancy, França.

3 Chefe do Serviço de Neurorradiologia Diagnóstica e Terapêutica do Centro Hospitalar Universitário de Nancy, França. 


\section{Introduction}

Between the causes of cortical hemorrhage, the distal aneurysms appear as a rare eventuality. When these aneurysms are encountered, the most common etiology is infection due to mycotic emboli with secondary aneurysm formation. The aneurysm etiology can be also traumatic or spontaneous dissections, neoplastic emboli (notably involving atrial myxoma and choriocarcinoma). Conceptually, there is still confusion as to the etiology, clinical, radiological features and treatment of aneurysms arising from one artery unrelated to branching zones.

Intracranial arteries dissections can cause brain ischemia and hemorrhage. Arterial dissection consists of mural tears with subsequent intramural hematoma formation. They may occur either spontaneously or as a consequence of traumatism. The treatment is usually clinical, but in some instances, intervention is indicated. The endovascular approach is an important tool, allowing specific treatment of the lesion in some cases, but sacrificing the artery in most cases.

Aneurysms secondary to dissection of the intracranial cerebral arteries tend to occur more proximally, including within the internal carotid artery, basilar artery, middle cerebral artery and posterior cerebral artery. More distal lesions (cortical arteries) have not been studied separately, to our knowledge.

With the aim of analyzing the clinical and technical aspects of the endovascular treatment, we studied retrospectively five patients with highly suggesting dissecting lesions.

\section{Methods}

\section{Patient population}

Between 2002 and 2005, the systematical review of 350 cases of intracranial hemorrhage (subarachnoid or intraparenchimal) treated in the University Central Hospital of Nancy, France, explored with 2D and 3D angiography, depicted five cortical dissection compatible cases.

The records of these five patients were reviewed. The factors assessed included clinical history, presentation, presence of SAH and its severity, aneurysm location, type of endovascular therapy, radiographically documented success of therapy, and clinical outcome.

The Research and Ethics Committee of the Pole of Neurosciences of the University Henri Poincare (Nancy I) approved the study.

\section{Results}

\section{Case reports}

\section{Case 1}

This 35-year-old 3-month pregnant woman, with antecedents of multiple sclerosis (stable), presented an abrupt onset of excruciating headache. The neurological findings were of meningeal irritation and somnolence, but no focal deficit. The CT scan showed left fronto-parietal intraparenchimal and subarachnoid hemorrhage. Four-vessels angiography showed an aneurysm of the right angular artery. Clinical and laboratorial investigation excluded the hypothesis of a mycotic aneurysm. After stabilization of the medical condition, the patient was treated by occlusion with coils of the aneurysm sac. The angiographic control showed the exclusion of the aneurysm and of the distal angular artery. The patient made a complete recovery, without speech abnormalities or any other neurological alteration (Figures 1A-D).

\section{Case 2}

This 35-year-old man had an abrupt onset of excruciating headache when he raised his 2-year-old nephew. The neurological findings were only neck stiffness.

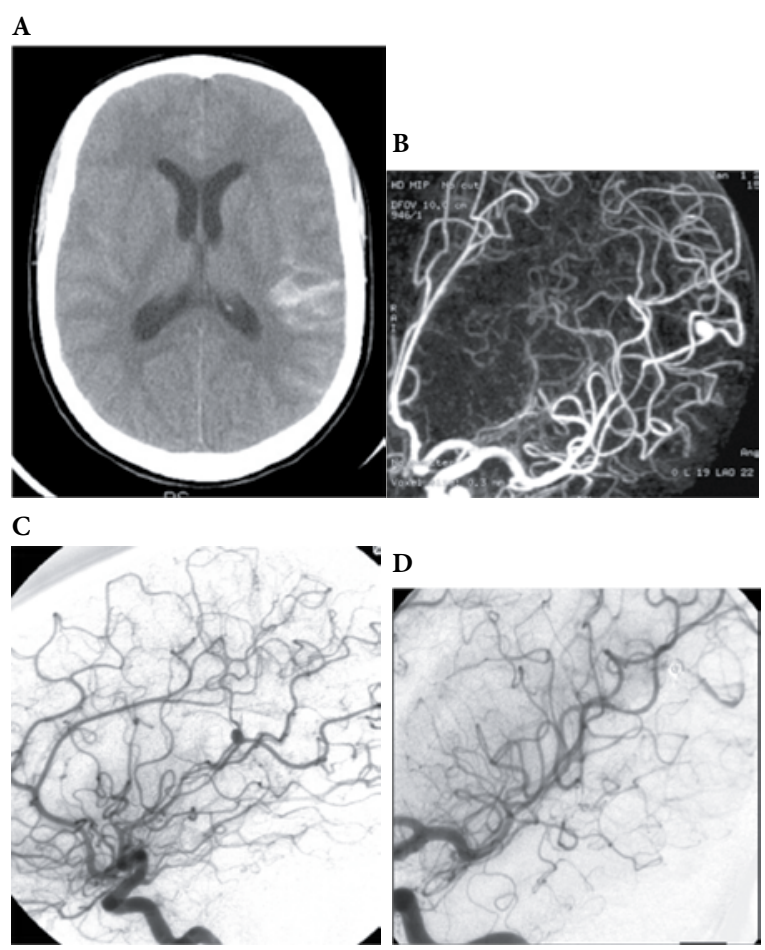

Figure 1 - Patient 1. (A) CT scan shows SAH with hematome. (B) DSA and $3 D(C)$ angiography with a fusiform aneurysm of the distal left angular artery. Note the stenose of the insular segment of this artery. (D) Angiographic control after coil occlusion at the aneurysm level. 
The CT scan revealed ambiens cistern blood. Injection through the left vertebral artery, during 4-vessels angiography, showed a small sacular dilatation of the $\mathrm{P} 2 / \mathrm{P} 3$ junction of the left posterior cerebral artery. The patient was treated conservatively; follow-up angiographies showed persistence of the occlusion of $\mathrm{P} 3$, without evolution of the little sacular dilatation (Figures 2A-E).

\section{Case 3}

This 44-year-old woman presented two episodes headache with right central facial palsy, with spontaneous resolution. The CT scan showed a centimetric left frontal hyperdense lesion. The MRI revealed a small cortical frontal lobe hematome. Four-vessel angiography showed stenosis of the left precentral artery. The patient was treated conservatively, and an angiographic

A

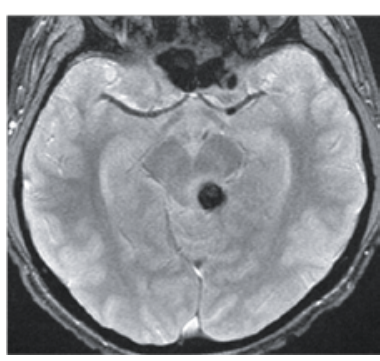

C

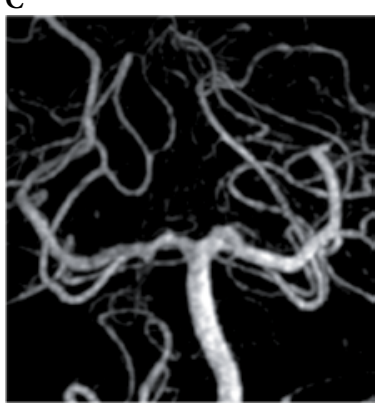

E

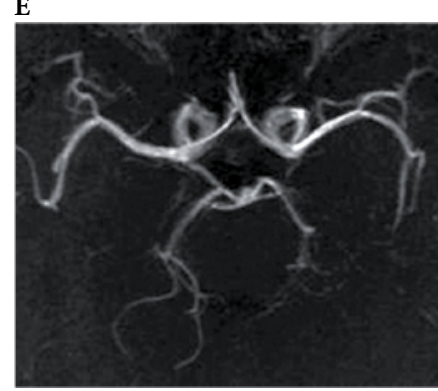

Figure 2 - Patient 2. (A) First day MRI with a tectal/cisternal left hematome with $(B)$ correspondent occlusion of the $P 3$ segment of the left posterior cerebral artery (3D-TOF MRI). The angiography made in the same day $(C)$ confirms the occlusion. Follow-up angiography in the $18^{\text {th }}$ day (D) depicts a discreet repermeabilization over a short segment of P3. 3D-TOF MRI after 3 months (E) shows persistence of the P3 occlusion, without aneurysmal development. control after one week and after eight months showed persistence of the occlusion of the precentral artery, without aneurysmal evolution, with vascularization of the affected territory by the cortico-pial anastomosis (Figures 3A-E).

\section{Case 4}

This 77-year-old woman sustained a massive subarachnoid hemorrhage and a cerebellar hematome caused by an aneurysm of the right postero-inferior cerebellar artery (PICA). The clinical findings were initially of an excruciating headache with loss of consciousness and nuchal rigidity. Angiography revealed a
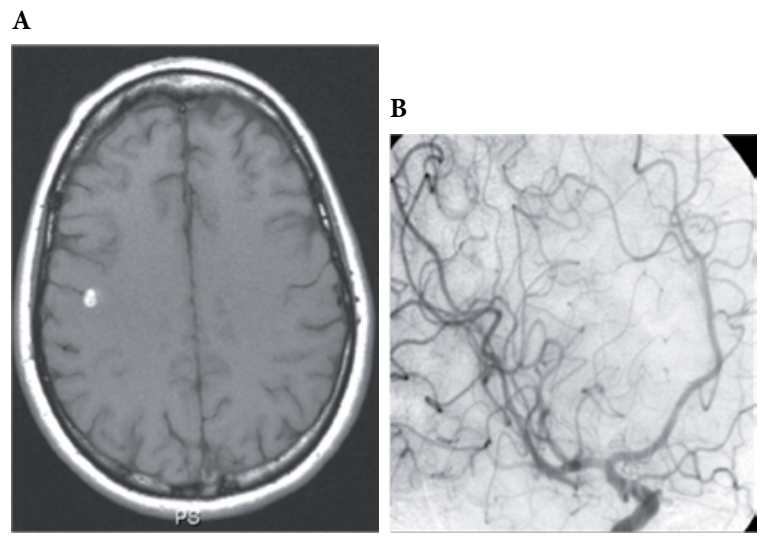

C
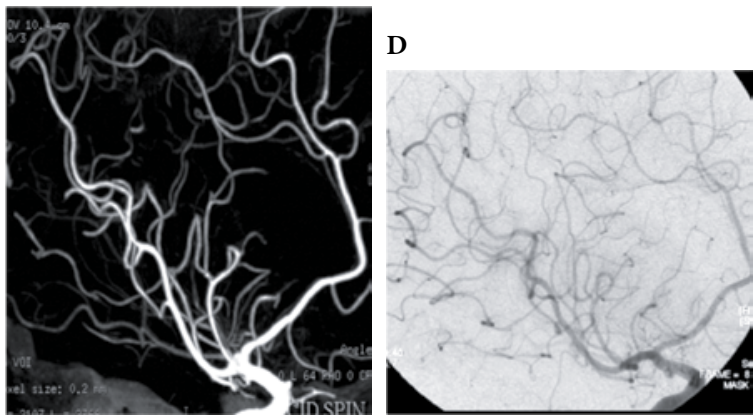

$\mathbf{E}$

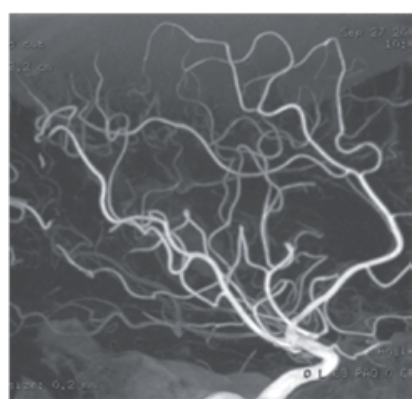

Figure 3 - Patient 3. (A) First day MRI with a little cortical frontal hematome. Left carotid oblique view DSA (B) and $3 D$ DSA $(C)$ in the same day shows a fusiform dilatation preceded by a zone of stenosis of the left precentral artery. Follow-up angiography after 8 months shows occlusion of the artery $(D, E)$. 
distal PICA aneurysm. The treatment was made in an urgent fashion, with coil occlusion of the aneurysm with preservation of the distal PICA. The post-embolization course was uneventful, and the patient was discharged with mild right dysmetry (Figures 4A-D).
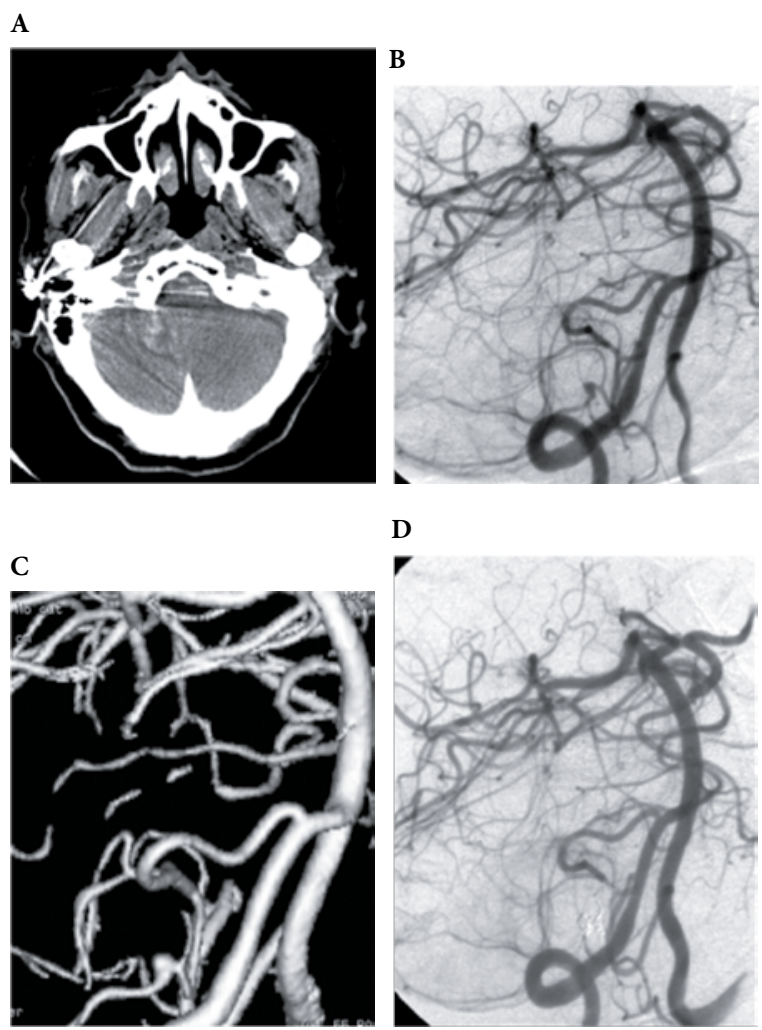

D

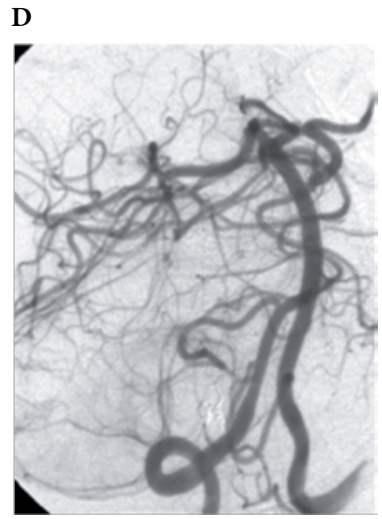

Figure 4 - Patient 4. (A) First day CT scan with SAH and right cerebellar hematome. $(B, C)$ Right vertebral DSA and $3 D$ angiography: fusiform aneurysm of the distal (cortical segment) right postero-inferior cerebellar artery. (D) Parent vessel occlusion at the aneurysm level, on the first day.

\section{Case 5}

This 63-year-old woman presented with sudden headache and confusion with agitation. The initial CT scan showed subarachnoid hemorrhage with a frontal interhemispheric hematome. An urgent angiogram depicted an aneurysm of the left pericalosal artery. In face of the importance of that artery, and the absence of an aneurysm neck, the surgical approach was considered first with the aim of preservation of the distal irrigation (Figure 5A-D).

As shown in table 1, the patients included four women and one man. The patients' age ranged from 35 to 77 years (mean age 50.8 years). No patient presented with a poor grade SAH (Hunt and Hess grade IV or V). All patients presented with headache.

The localization of the vessel abnormality was equally distributed between the anterior and posterior circulation. All patients, except case $n^{\circ} 3$, harbored an aneurysmal sac angiographically detectable.
A
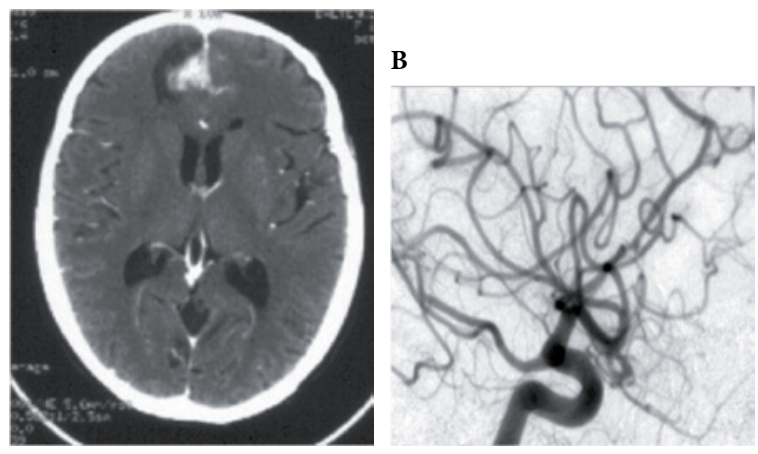

C

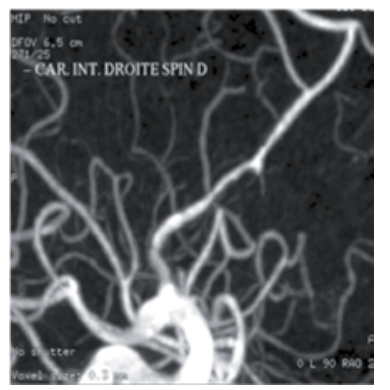

D

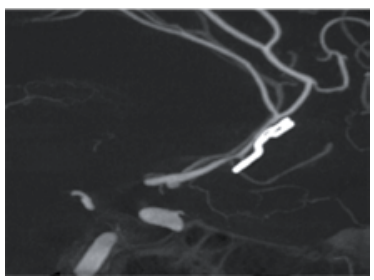

Figure 5 - Patient 5. First-day CT scan (A) with SAH and interhemispheric frontal hematome $(B, C)$ Same day right carotid $D S A$ with $3 D$ reconstruction: irregular stenosis followed by a fusiform aneurysm of the right pericalosal artery. (D) 3D DSA postsurgical control.

\begin{tabular}{|c|c|c|c|c|c|c|}
\hline \multicolumn{7}{|c|}{$\begin{array}{l}\text { Table } 1 \text { - Clinical characteristics and } \\
\text { lesion topography of } 5 \text { patients }\end{array}$} \\
\hline $\begin{array}{l}\text { Case } \\
n^{\circ}\end{array}$ & $\begin{array}{l}\text { Age } \\
\text { (Yrs) }\end{array}$ & Sex & $\begin{array}{l}\text { Type and site } \\
\text { of lesion }\end{array}$ & $\begin{array}{l}\text { Clinical } \\
\text { presentation }\end{array}$ & $\begin{array}{l}\text { Hunt } \\
\text { and } \\
\text { Hess } \\
\text { grade }\end{array}$ & $\begin{array}{l}\text { Associated } \\
\text { factors/risk } \\
\text { factors (?) }\end{array}$ \\
\hline 1 & 35 & $\mathrm{~F}$ & $\begin{array}{l}\text { SAH/left } \\
\text { parietal } \\
\text { hematome } \\
\text { Aneurysm. } \\
\text { Artery angular }\end{array}$ & $\begin{array}{l}\text { Headache. } \\
\text { Drowsiness. } \\
\text { Meningeal } \\
\text { irritation }\end{array}$ & III & $\begin{array}{l}\text { Pregnancy } \\
\text { (3 months) } \\
\text { Multiple } \\
\text { sclerosis }\end{array}$ \\
\hline 2 & 35 & M & $\begin{array}{l}\text { Hematome (left } \\
\text { perimesence- } \\
\text { phalic cistern) } \\
\text { Aneurysm. } \\
\text { P2/P3 }\end{array}$ & Headache & II & $\begin{array}{l}\text { Discreet } \\
\text { physical } \\
\text { effort }\end{array}$ \\
\hline 3 & 44 & $\mathrm{~F}$ & $\begin{array}{l}\text { Frontal left } \\
\text { hematome } \\
\text { Stenosis and } \\
\text { dilatation. } \\
\text { Left precentral } \\
\text { artery }\end{array}$ & $\begin{array}{l}\text { Headache. } \\
\text { Right } \\
\text { central facial } \\
\text { paralysis }\end{array}$ & I & Smoking \\
\hline 4 & 77 & $\mathrm{~F}$ & $\begin{array}{l}\text { Right cerebellar } \\
\text { hematome. } \\
\text { SAH } \\
\text { Aneurysm. } \\
\text { PICA distal }\end{array}$ & $\begin{array}{l}\text { Headache, } \\
\text { loss of cons- } \\
\text { ciousness, } \\
\text { meningeal } \\
\text { irritation }\end{array}$ & III & No \\
\hline 5 & 63 & $\mathrm{~F}$ & $\begin{array}{l}\text { Interhemisphe- } \\
\text { ric hemato- } \\
\text { me. SAH } \\
\text { Aneurysm. Pe- } \\
\text { ricallosal artery }\end{array}$ & $\begin{array}{l}\text { Headache. } \\
\text { Meningeal } \\
\text { irritation. } \\
\text { Confusion } \\
\text { and agitation }\end{array}$ & III & No \\
\hline
\end{tabular}

PICA: postero-inferior cerebellar artery; P2/P3: between the second and the third segment of the posterior cerebral artery. 


\section{Endovascular procedures}

As shown in table 2, standard endovascular methods of parent artery coil occlusion and aneurysm coil occlusion were used.

\begin{tabular}{|c|c|c|c|}
\hline \multicolumn{4}{|c|}{$\begin{array}{c}\text { Table } 2 \text { - Location of the dissection, treatment } \\
\text { options and outcome in } 5 \text { patients }\end{array}$} \\
\hline $\begin{array}{l}\text { Case } \\
n^{\circ}\end{array}$ & Location & Treatment & GOS score \\
\hline 1 & $\begin{array}{l}\text { Aneurysm. Artery } \\
\text { angular }\end{array}$ & $\begin{array}{l}\text { Parent artery } \\
\text { coil occlusion }\end{array}$ & 5 \\
\hline 2 & Aneurysm. P2/P3 & Conservative & 5 \\
\hline 3 & $\begin{array}{l}\text { Stenosis and dilatation. } \\
\text { Left precentral artery }\end{array}$ & Conservative & 5 \\
\hline 4 & Aneurysm. PICA distal & $\begin{array}{l}\text { Aneurysmal coil } \\
\text { occlusion }\end{array}$ & 4 \\
\hline 5 & $\begin{array}{l}\text { Aneurysm. } \\
\text { Pericallosal artery }\end{array}$ & Surgery (clipping) & 4 \\
\hline
\end{tabular}

GOS: Glasgow Outcome Scale $(5=$ good recovery; $4=$ moderate disability; $3=$ severe disability; 2 = vegetative state; 1 = death)

\section{Discussion}

The term "arterial dissection" was first used ${ }^{1}$ by René Laennec in 1819 although Morgagni had already made the first description of an arterial dissection in 1769. Turnbull ${ }^{2}$ apparently first described the notion of the evolution possibility of a dissection into a pseudoaneurysm in 1915 (apud Friedman and Drake ${ }^{3}$ ); this author described a syphilitic arteritis-related dissecting middle cerebral aneurysm. In 1972, Ojeman et al. ${ }^{4}$ named "string sign" the area of stenosis in the internal carotid artery in a surgical and pathologically confirmed case of dissection. Kunze and Schiefer ${ }^{5}$ had described a more specific angiographic appearance of cerebral dissecting aneurysm in 1971: the visualisation of flow in both true and false lumens.

Yonas et al. ${ }^{6}$, in 1977, made perhaps the first description of an angiographic diagnostic of an intracranial dissection (dissecting aneurysm of the vertebral artery) followed by surgical treatment. During the decade of 1980 and 1990, the commonest site of cranio-cervical dissecting aneurysms, the vertebral artery, has been extensively studied. ${ }^{7}$

\section{Etiology}

The spontaneous arterial dissections occur more frequently in patients with migraine, Ehlers-Danlos and Marfan syndrome, type 1 neurofibromatosis (arteriovenous fistule and dissections of the vertebral cervical artery). ${ }^{8}$

The cause of spontaneous cervicocerebral artery dissections is unknown. An underlying arteriopathy due to a connective tissue disorder has often been presumed. ${ }^{9}$ Brandt et al. ${ }^{10}$ studied the skin of 25 patients with proven nontraumatic intracranial dissections, and found ultrastructural abnormalities in 17 (68\%) patients, resembling in some cases the aberrations found in Ehlers-Danlos syndrome type II or III.

A disorder that may well be confused with cranial dissecting aneurysm is fibromuscular dysplasia. Mizutani et al. ${ }^{11}$ suggests that the several case reports of intracranial fibromuscular dysplasia published in the 70's with the diagnosis based solely on the "string of beads" sign in the affected cerebral arteries seen on angiography, were probably arterial dissections. Nowadays is acceptable that fibromuscular dysplasia typically involves the extracranial portion of the ICA, and spares intracranial arteries.

The literature on fusiform aneurysms is complicated by the confusing nomenclature consisting of numerous terms, some of which are descriptive, and some of which are based on a pathogenesis that is unproven. ${ }^{12,13}$ Based on the spectrum of clinical, pathological, neuroimaging and intraoperative findings in 102 cases of spontaneous fusiform middle cerebral artery aneurysms, Day raises the proposition that dissection is the underlying cause of these lesions. ${ }^{14}$

The diagnosis of mycotic aneurysm relies on the positivity of blood cultures and/or endocarditis. ${ }^{15}$ Older series do not expressly show these fundamental diagnostic criteria, and we can raise the question if many related mycotic aneurysms were dissecting ones.

In our series of five patients, we have not been able to identify any predisposing or risk factor. No patient had arterial hypertension, and the careful revision of the angiographic series didn't show any sign of dysplasic blood vessels.

\section{Epidemiology}

The intracranial dissections with SAH published in the literature $\mathrm{e}^{3,6,7,16,17}$ in a total of 63 cases, the age ranged from 25 to 77 years (mean age of 54,5 years). A male predominance $(5: 2)$ is noticed.

Spontaneous intracranial dissections (with or without SAH), were found in just two cases $(0.04 \%)$ in a series of 4,531 cerebral angiograms. ${ }^{18}$

In our series of five patients, we have noticed female predominance.

\section{Pathology}

Dissection without hemorrhage (ischemic cases, asymptomatic cases) - The cases with cerebral ischemia are characterized by a subintimal plane of dissection (between the internal elastic lamina and the media), 
causing a hematome that compress the true arterial lumen. The dissection may extend to the more distal branches. ${ }^{11,19}$ Dissecting aneurysms in the anterior circulation rarely manifest as hemorrhage, and thus their natural history after hemorrhage is unclear. ${ }^{20}$ Dissection of more distal arteries do not always end in aneurysmal formation, but it's necessary however to repeat DSA or MRA to detect any aneurysmal change in the dissecting artery. ${ }^{21}$

Dissections with SAH - The substantial mechanism of the classic dissecting aneurysm presenting with $\mathrm{SAH}$ is an acute disruption of the internal elastic lamina (IEL). The rebleeding incidence varies in the different series in the literature, with more than $70 \%$ in the series of Mizutani et al. ${ }^{17}$

True aneurysms are saccular or fusiform outpouchings of all layers of a vessel wall. False aneurysms are characterized by incomplete or complete disruption of the wall, with formation of a secondary lumen which can be contained by a layer of the wall or organized hematoma. They include mycotic, traumatic and dissecting aneurysms. In the last form, there is a plane of dissection between the internal elastic lamina (IEL) and the media with rare extension into the adventitia (the latter may result in subarachnoid hemorrhage).

The strength of a normal vessel wall has been attributed to the IEL: this layer includes abundant elastin and collagen fibers, vital to the strength of arterial wall. The damage to the IEL is probably the main factor in aneurysm formation. ${ }^{16,22}$

The commonly observed pathological features in a dissecting aneurysm are widespread disruption of the IEL without intimal thickening and the presence of a pseudolumen. In the area of disrupted IEL, the aneurysm wall comprised fragile adventitia or connective tissue. Lack of intimal thickening confirms that dissecting aneurysms are formed in an acute process. ${ }^{13}$ In a series of 58 autopsies in patients with fatal SAH caused by vertebral artery dissections, pathological evidence of a previous healed dissection with an associated internal elastic lamina disruption was found in $43 \%$ of cases. ${ }^{23}$

Rupture of vasa vasorum or rupture of new vessels formed in response to medial ischemia and necrosis would be responsible in dissections with SAH without lumen communication. Although vasa vasorum are not present in all intradural arteries (they are found in the vertebrobasilar system and ICA), associated atheromatous diseases increases their presence. ${ }^{6}$

Dissections occur in the portions of the extracranial vertebral arteries that are most freely movable. These are the third portion of the vertebral artery that extends around the upper cervical vertebrae and the first portion of the vertebral artery between its origin and its entrance into the intervertebral foramina. ${ }^{24}$ Contributing factors may be the presence of a relatively major change in structure of the vertebral artery as it enters the skull: diminution in thickness of the adventitia and media and a very gross reduction or loss of elastic fibers in the media and external lamina. ${ }^{25}$

In one case ${ }^{9}$ of dissecting aneurysm of the posterior inferior cerebellar artery (PICA) uninvolved with the vertebral artery, histopathological findings showed the segmental mediolytic arteriopathy probably involved in the pathogenesis.

\section{Diagnostic}

In our series of five patients, the inclusion criteria ${ }^{16,26}$ were:

1. CT scan with HSA or intraparenchimal hemorrhage;

2. Cortical artery involvement on angiography, with aneurysmal dilatation (fusiform or saccular with large neck), with or without stagnation of the contrast media;

3. Segmentar stenose with irregular arterial wall.

The exclusion criteria were:

1. Absence of a localized abnormality in a single vessel (as occurs in atherosclerotic disease, vasculitis and vasospasm);

2. Proximal artery involvement;

3. Major trauma, recent infection.

Clinical criteria: Sudden onset of ischemic or hemorrhagic symptoms. The most common symptom of vertebrobasilar dissection before onset of brain-stem dysfunction is headache (with pain usually in the occipital and posterior cervical regions, and intensified immediately before clinical deterioration). In our cases of cortical dissection, the onset was variable, with headache in $100 \%$ of the patients, but with a moderate intensity (except for the PICA distal case). We had meningeal irritation in the cases with SAH. The other symptoms were topography-depending (contralateral facial paralysis in case 3 and confusion with psycomotor agitation in case 5).

Angiographic criteria: for spontaneous dissections:

The angiographic criteria of intracranial dissections are classically:

- The double-lumen sign with intimal flap;

- The "pearl-and-string" sign;

- The evolutive (changing) aspect of the lesions over the time on different angiographies.

A dissecting aneurysm appears as a saccular dilatation, frequently with a large neck, or a more fusiform appearance, ${ }^{6}$ with irregular limits, associated with a narrowing of the arterial lumen. Stagnation of contrast in the aneurysm pouch may be observed. The question "is an aneurysm or a pseudoaneurysm?" cannot be answered exclusively 
by angiographic criteria, since that difference is anatomopathological. The former harbours the three parts of the arterial wall (although in abnormal proportions), and the latter the wall is incomplete. Even though that distinction, the terms are used seldom in the literature.

The double-lumen sign (the visualization of both true and false arterial lumen) and the presence of a visible intimal flap are the only pathognomonic angiographic features, but rarely observed. We had no case in our series. This may be caused by the size of the involved vessels and the resolution of angiography. An important detail is that the narrowing distal to the ectasia, regardless of its appearance, is to be considered the very end of the dissected portion. ${ }^{27}$

Stenosis with dilatation (the "pearl and string sign") was noted in the case of PICA distal dissection (case 4 ), and in a form less characteristic in the pericalosal case $\left(n^{\circ} 5\right)$.

However, in cases of stenosis without dilatation (the "string sign", which represents a narrow, tapered lumen secondary to the subintimal hematoma) and of stenosis with dilatation without pseudoaneurysm, since cerebral vasculitis or idiopathic reversible diffuse angiopathy can show similar abnormalities its necessary to confirm dissection ${ }^{28}$ with double lumen or intimal flap on angiography and retention of contrast material into the late venous phase, the discoloration of the affected artery (due to the intramural hematoma) seen on operation, or high signal on the vessel wall on MRI. The finding of stenosis with a dilatation may be considered as a sign of dissection because of the topography correspondence with a hematoma, and absence of other area of abnormalities in the totality of angiographic examination. Because dissection is a dynamic process, ${ }^{26}$ we rely in the changing aspect on follow-up angiography in patients as the case 3 (involving the left precentral artery) was considered a distal dissection in the absence of other possibility and in face of the evolution (resolution of the stenosis was seen on follow-up angiography).

MRI criteria: High signal around the luminal signal void on T1- weighted images is an indication of the intramural hematoma. The mural hematoma was not seen in any of our cases, probably because of the small calibre of the affected arteries. However, high-resolution IRM may well demonstrate the hematoma, even in distal arteries. ${ }^{29}$ Although MRI cannot reliably distinguish an intramural hematoma from an intraluminal thrombus, ${ }^{30}$ it can be useful in cases of subadventitial dissection without narrowing of the arterial lumen or when the dissecting aneurysm is thrombosed. In these two cases, the accuracy of catheter angiography is limited.

In contrast MR, enhancement of the dissecting aneurysm with gadolinium is seen in $95 \%$ of cases; ring-like or railroad-like enhancement (includes the entire vessel wall with a central or eccentric signal flow void) may be seen. This enhancement disappears when the dissecting aneurysm disappears on the angiogram. MRI in smaller arteries may not indicate whether the thrombus is intra or extra-luminal. ${ }^{31,32}$ Even in greater vessels, this finding cannot substitute angiography. ${ }^{18}$

Treatment options: There is no randomized trial data determining the optimal management strategy for patients with intracranial dissections. In the cases of dissections with ischemic symptoms, surgery (including bypass) or endovascular treatment does not seem to be effective, since it cannot improve flow through the perforating lenticulostriate arteries obstructed by the dissection itself. ${ }^{19}$ The patients with unrupted dissecting aneurysms (without expansive effect) have a high frequency of spontaneous resolution; so the treatment is indicated only if the control angiography shows persistence or increasing in size of the lesion. Although anticoagulation is advocated in extracranial dissections, its use in intracranial dissections has not been promoted due to the risk of mural hemorrhage, rupture or extension of the lesion. ${ }^{16,31}$ Antiplatelet therapy is an alternative to anticoagulation that may provide antithrombotic protection with a lower risk of hemorrhage. ${ }^{33}$

In the cases of dissections with SAH: early intervention (in acute stage) is strongly recommendend. ${ }^{34}$ The recurrence of SAH is frequent: Mizutani ${ }^{11}$, in a series of 42 patients with untreated ruptured vertebrobasilar dissecting aneurysm, had 30 patients $(71.4 \%)$ with rebleeding. Of these, 14 patients died (46.7\%). The rebleeding during the first 24 hours occurred in 17 of the 30 patients $(56.7 \%)$ showing that intracranial dissections are dynamic lesions, with a significant risk or hemorrhage. The risk of rebleeding seems to be greater than that for saccular aneurysms. ${ }^{17,35}$

Unlike saccular aneurysms, there are few established treatment modes for the management of dissecting aneurysms. The methods of treatment may be surgical or endovascular. In ruptured dissecting aneurysms both methods seems to offer significant benefit; in a series of ruptured vertebrobasilar dissecting aneurysms, the mortality rate in the treated group was $20 \%$, whereas that in the untreated group was $50 \% .^{36}$

The techniques used in both methods may be divided in deconstructive and reconstructive. The former are based in interrupting the arterial flux before (and sometimes also after) the aneurysm, and the latter in trying to fix the arterial lumen with its preservation, while isolating the sick segment of the systemic circulation.

\section{a) Deconstructive methods}

Surgery: Hunter first introduced his method in 1839 (apud Friedman and Drake ${ }^{3}$ ). The rationale for the "hunterian ligation" use is that the interruption of the 
flux will reduce the intravascular pressure, favouring the thrombose and that in selected cases, the anatomical anastomoses will compensate the loss of one artery. Multiple surgical approaches have been used: proximal occlusion and trapping. Nussbaum et al. ${ }^{37}$ in an attempt to avoid brainstem perforators' occlusion, performed three cases of distal occlusion of complex dissecting PICA aneurysms; the rationale for this approach lies in the diminution in the amount of flow through the occluded artery, and although the pressure within the aneurysm may momentarily increase, it should rapidly diminish thereafter.

Endovascular: Occlusion of the parent artery at the level of the dissection site with coils, resulting in flow reversal, makes possible the obliteration of the entire dissected segment, a procedure that is easier than surgical trapping of the site of dissection, especially regarding the distal side of the parent artery. ${ }^{38}$ The endovascular method has also the advantage of permitting a test occlusion. Depending on the artery, the site of the test occlusion is critical. In the case of the vertebral artery, proximal test occlusion is often tolerated due to the plethora of available surrounding collateral vessels. This does not imply that distal occlusion of vertebral arteries will be tolerated. Therefore, test occlusion should be performed at or just proximal to the intended site of permanent occlusion. ${ }^{38,39}$

\section{b) Reconstructive techniques}

Surgery: The clipping of the aneurysm is difficult (no aneurysm neck, and difficulties in surgical dissection of a sick artery): the two patients treated by Mizutani et al. ${ }^{17}$ died. The "wrapping" (protection of the aneurysm sac with muscle and/or acrylic) also involves the risk or surgical dissection, as also does the "trapping" (entrapment of the involved segment with clips).

The skull-base and far-lateral transcondylar surgical approaches are useful in cases where the aneurysm involves the origin of a PICA in a dominant vertebral artery: the vessel may be sacrificed after a bypass (PICA to PICA). ${ }^{39}$

In our case of pericallosal artery aneurysm, the option of a surgical approach was of trying preserving the flux in that artery, which was successful.

Endovascular: Coiling of the aneurysm with preservation of the parent artery is extremely difficult and dangerous. In the case of patient 4 (distal PICA), the preservation of the artery distal to the aneurysm was not planned; the occlusion was acceptable as the perforating branches emanate from the first three segments of the PICA. ${ }^{40}$ Thus sacrificing the PICA at the distal aspect of the tonsilomedulary segment would be probably well tolerated, as it was.

Intravascular stenting and endosaccular coiling ${ }^{41,42}$ are the other option to treat ruptured dissecting aneurysms. The long-term efficacy and durability of stent placement for arterial dissections needs to be confirmed in large series.

The optimal treatment of intracranial dissecting aneurysm has been controversial. ${ }^{24,34,38,39}$ The most appropriate treatment should be selected according to the anatomical location of the aneurysm, the anatomical relationship between the parent artery and the perforating arteries, and the extent of the dissection.

\section{Conclusion}

The natural history of dissecting aneurysms involving cortical arteries is not well documented. Evidence from reported cases suggests a more benign outcome than with dissecting aneurysms affecting the vertebrobasilar system. In our series, all the patients have been classified as good recovery or moderate disability. The real frequency of intracranial cortical dissections is probably under-related. The careful angiographic examination with multiple $2 \mathrm{D}$ and $3 \mathrm{D}$ acquisitions associated to the clinical context, and most important, the exclusion of an infectious syndrome will direct the diagnosis. The MRI images may be of fundamental importance whenever an intramural hematome is detected.

In the aneurysmal with SAH forms, the treatment in an urgent fashion must be considered in face of the risk of rebleeding. The first-choice logical treatment seems to be coil occlusion of the involved artery at the level of the dissection. This manoeuvre is perhaps a little less complicated than when a large arterial occlusion is considered in the classical proximal dissections, however, the topography versus clinical consequence of occlusion must be weighted before.

If the clinical context or topography of the lesion is not favorable to occlusion, this treatment may be postponed. In this case, a follow-up angiography must be done, with changing in the therapeutic option according to the result.

\section{Competing interests}

The authors declare no conflict of interest.

\section{References}

1. Pasquier B, Couderc P, Pasquier D, Panh MH, N'Golet A, Pellat J. Obliterating parietal hemodissection or vertebrobasilar dissecting aneurysm. Sem Hop. 1976;52(44):2519-27. 
2. Turnbull HM. Alterations in arterial structure, and their relationship to syphilis. QJM. 1915;8:201-54.

3. Friedman AH, Drake CG. Subarachnoid hemorrhage from intracranial dissecting aneurysm. J Neurosurg. 1984;60(2):325-34.

4. Ojemann RG, Fisher CM, Rich JC. Spontaneous dissecting aneurysm of the internal carotid artery. Stroke. 1972;3(4):434-40.

5. Kunze S, Schiefer W. Angiographic demonstration of a dissecting aneurysm of the middle cerebral artery. Neuroradiology. 1971;2(4):201-6.

6. Yonas H, Agamanolis D, Takaoka Y, White RJ. Dissecting intracranial aneurysms. Surg Neurol. 1977;8(6):407-15.

7. Caplan LR, Baquis GD, Pessin MS, D'Alton J, Adelman LS, DeWitt LD, et al. Dissection of the intracranial vertebral artery. Neurology. 1988;38(6):868-77.

8. Schievink WI. Spontaneous dissection of the carotid and vertebral arteries. N Engl J Med. 2001;344(12):898-906.

9. Yamakawa H, Kaku Y, Yoshimura S, Ohkuma A, Sakai N. Two cases of dissecting aneurysm of the distal posterior inferior cerebellar artery: possible involvement of segmental mediolytic arteriopathy in the pathogenesis. Clin Neurol Neurosurg. 2005;107(2):117-22.

10. Brandt T, Hausser I, Orberk E, Grau A, Hartschuh W, Anton-Lamprecht I, et al. Ultrastructural connective tissue abnormalities in patients with spontaneous cervicocerebral artery dissections. Ann Neurol. 1998;44(2):281-5.

11. Mizutani T, Goldberg HI, Parr J, Harper C, Thompson CJ. Cerebral dissecting aneurysm and intimal fibroelastic thickening of cerebral arteries. Case report. J Neurosurg. 1982;56(4):571-6.

12. Yasui T, Komiyama M, Nishikawa M, Nakajima H, Kobayashi $\mathrm{Y}$, Inoue T. Fusiform vertebral artery aneurysms as a cause of dissecting aneurysms. Report of two autopsy cases and a review of the literature. J Neurosurg. 1999;91(1):139-44.

13. Mizutani T, Miki Y, Kojima H, Suzuki H. Proposed classification of nonatherosclerotic cerebral fusiform and dissecting aneurysms. Neurosurgery. 1999;45(2):253-9.

14. Day AL, Gaposchkin CG, Yu CJ, Rivet DJ, Dacey RG Jr. Spontaneous fusiform middle cerebral artery aneurysms: characteristics and a proposed mechanism of formation. J Neurosurg. 2003;99(2):228-40.

15. Chapot R, Houdart E, Saint-Maurice JP, Aymard A, Mounayer C, Lot G, et al. Endovascular treatment of cerebral mycotic aneurysms. Radiology. 2002;222(2):389-96.

16. Berger MS, Wilson $\mathrm{CB}$. Intracranial dissecting aneurysms of the posterior circulation. Report of six cases and review of the literature. J Neurosurg. 1984;61(5):882-94.

17. Mizutani T, Aruga T, Kirino T, Miki Y, Saito I, Tsuchida T. Recurrent subarachnoid hemorrhage from untreated ruptured vertebrobasilar dissecting aneurysms. Neurosurgery. 1995;36(5):905-11.

18. Biller J, Hingtgen WL, Adams HP Jr, Smoker WR, Godersky JC, Toffol GJ. Cervicocephalic arterial dissections. A tenyear experience. Arch Neurol. 1986;43(12):1234-8.

19. Ohkuma H, Suzuki S, Shimamura N, Nakano T. Dissecting aneurysms of the middle cerebral artery: neuroradiological and clinical features. Neuroradiology. 2003;45(3):143-8.

20. Amagasaki K, Yagishita T, Yagi S, Kuroda K, Nishigaya K, Nukui $\mathrm{H}$. Serial angiography and endovascular treatment of dissecting aneurysms of the anterior cerebral and vertebral arteries. Case report. J Neurosurg. 1999;91(4):682-6.

21. Hidaka D, Toyoda K, Fujimoto S, Yasumori K, Okada Y. Ischemic stroke in a young adult due to dissection of a branch of the middle cerebral artery. Intern Med. 2005;44(5):505-6.
22. Yamaura A, Watanabe $Y$, Saeki N. Dissecting aneurysms of the intracranial vertebral artery. J Neurosurg. 1990;72(2):183-8.

23. Ro A, Kageyama N, Abe N, Takatsu A, Fukunaga T. Intracranial vertebral artery dissection resulting in fatal subarachnoid hemorrhage: clinical and histopathological investigations from a medicolegal perspective. J Neurosurg. 2009;110(5):948-54.

24. Yamaura I, Tani E, Yokota M, Nakano A, Fukami M, Kaba $\mathrm{K}$, et al. Endovascular treatment of ruptured dissecting aneurysms aimed at occlusion of the dissected site by using Guglielmi detachable coils. J Neurosurg. 1999;90(5):853-6.

25. Wilkinson IM. The vertebral artery. Extracranial and intracranial structure. Arch Neurol. 1972;27(5):392-6.

26. Ohkuma H, Suzuki S, Ogane K; Study Group of the Association of Cerebrovascular Disease in Tohoku, Japan. Dissecting aneurysms of intracranial carotid circulation. Stroke. 2002;33(4):941-7.

27. Lim SM, Choi IS, Hum BA, David CA. Dissecting aneurysms of the distal segment of the posterior inferior cerebellar arteries: clinical presentation and management. AJNR Am J Neuroradiol. 2010;31(6):1118-22.

28. Nussbaum ES, Madison MT, Goddard JK, Lassig JP, Nussbaum LA. Peripheral intracranial aneurysms: management challenges in 60 consecutive cases. J Neurosurg. 2009;110(1):7-13.

29. Moro N, Katayama Y, Oshima H, Kano T. Sagittal magnetic resonance imaging of intramural hematoma from nontraumatic dissection of the anterior cerebral artery. Case report. Neurol Med Chir (Tokyo). 2005;45(6):300-5.

30. Zuber M, Meary E, Meder JF, Mas JL. Magnetic resonance imaging and dynamic CT scan in cervical artery dissections. Stroke. 1994;25(3):576-81.

31. Lazinski D, Willinsky RA, TerBrugge K, Montanera W. Dissecting aneurysms of the posterior cerebral artery: angioarchitecture and a review of the literature. Neuroradiology. 2000;42(2):128-33.

32. Nagahiro S, Hamada J, Sakamoto Y, Ushio Y. Follow-up evaluation of dissecting aneurysms of the vertebrobasilar circulation by using gadolinium-enhanced magnetic resonance imaging. J Neurosurg. 1997;87(3):385-90.

33. Chaves C, Estol C, Esnaola MM, Gorson K, O'Donoghue $M$, De Witt LD, et al. Spontaneous intracranial internal carotid artery dissection: report of 10 patients. Arch Neurol. 2002;59(6):977-81.

34. Anxionnat R, de Melo Neto JF, Bracard S, Lacour JC, Pinelli C, Civit T, et al. Treatment of hemorrhagic intracranial dissections. Neurosurgery. 2003;53(2):289-300.

35. Yamada M, Kitahara T, Kurata A, Fujii K, Miyasaka Y. Intracranial vertebral artery dissection with subarachnoid hemorrhage: clinical characteristics and outcomes in conservatively treated patients. J Neurosurg. 2004;101(1):25-30.

36. Rabinov JD, Hellinger FR, Morris PP, Ogilvy CS, Putman CM. Endovascular management of vertebrobasilar dissecting aneurysms. AJNR Am J Neuroradiol. 2003;24(7):1421-8.

37. Nussbaum ES, Madison MT, Goddard JK, Lassig JP, Janjua TM, Nussbaum LA. Remote distal outflow occlusion: a novel treatment option for complex dissecting aneurysms of the posterior inferior cerebellar artery. Report of 3 cases. J Neurosurg. 2009;111(1):78-83.

38. Hamada J, Kai Y, Morioka M, Yano S, Todaka T, Ushio Y. Multimodal treatment of ruptured dissecting aneurysms of the vertebral artery during the acute stage. J Neurosurg. 2003;99(6):960-6.

39. Lewis SB, Chang DJ, Peace DA, Lafrentz PJ, Day AL. Distal posterior inferior cerebellar artery aneurysms: clinical features and management. J Neurosurg. 2002;97(4):756-66. 
40. Lister JR, Rhoton AL Jr, Matsushima T, Peace DA. Microsurgical anatomy of the posterior inferior cerebellar artery. Neurosurgery. 1982;10(2):170-99.

41. Meder JF, Bracard S, Arquizan C, Trystram D, Frédy D. Endovascular treatment using endoprosthesis and metallic stents for aneurysmal dissection of the intracranial vertebral artery. J Neuroradiol. 2001;28(3):166-75.

42. Ahn JY, Han IB, Kim TG, Yoon PH, Lee YJ, Lee BH, et al. Endovascular treatment of intracranial vertebral artery dissections with stent placement or stent-assisted coiling. AJNR Am J Neuroradiol. 2006;27(7):1514-20.

\section{Correspondence address}

Carlos Michel Albuquerque Peres

Av. Ayrão, 507, sala 14, Hospital Santa Júlia

69025-050 - Manaus, AM, Brazil

Telephone: (55 92) 32341395

E-mail: cmaperes@mac.com 